\title{
Effects of Therapies on Cardiovascular Events in Ankylosing Spondylitis: A Systematic Review and Meta-Analysis
}

\author{
Paras Karmacharya (D) - Ravi Shahukhal · Cynthia S. Crowson • \\ M. Hassan Murad · John M. Davis III · Pragya Shrestha • \\ Delamo Bekele $\cdot$ Kerry Wright $\cdot$ Rikesh Chakradhar · Maureen Dubreuil
}

Received: September 16, 2020 / Accepted: October 19, 2020 / Published online: November 10, 2020

(C) The Author(s) 2020

\section{ABSTRACT}

Introduction: Non-steroidal anti-inflammatory drugs (NSAIDs) and tumor necrosis factor inhibitors (TNFi) are the most common therapies used in AS, however, the associated long-term cardiovascular risk is unclear. We performed a

Electronic Supplementary Material The online version of this article (https://doi.org/10.1007/s40744020-00248-x) contains supplementary material, which is available to authorized users.

P. Karmacharya $(\bowtie) \cdot$ C. S. Crowson .

J. M. Davis III · D. Bekele · K. Wright .

R. Chakradhar

Division of Rheumatology, Mayo Clinic, Rochester, MN, USA

e-mail: paraskarmacharya@gmail.com

R. Shahukhal

Lakes Regional General Hospital, Laconia, NH, USA

C. S. Crowson

Division of Biomedical Statistics and Informatics, Department of Health Sciences Research, Mayo

Clinic, Rochester, MN, USA

M. H. Murad

Evidence-Based Practice Center, Mayo Clinic, Rochester, MN, USA

P. Shrestha

Precision Population Science Lab, Mayo Clinic, Rochester, MN, USA

M. Dubreuil

Boston University School of Medicine, Boston, MA, USA systematic review and meta-analysis on the association of therapies used for ankylosing spondylitis (AS) such as NSAIDs and TNFi on cardiovascular events (CVE) in AS.

Methods: A comprehensive search was performed from database inception to May 29, 2020 to include controlled studies of AS treated with NSAIDs, oral small molecules, or biologics reporting CVE. Study-specific risk ratios (RR) were pooled using a random effects model.

Results: Nine non-randomized studies from 1570 studies screened fulfilled inclusion criteria. Among NSAID users as a whole versus no NSAIDs, no increased risk of CVE (composite outcome) was observed; however, the risk of cerebrovascular accident was significantly lower (RR 0.58, 95\% CI 0.37-0.93, $I^{2}=66 \%$ ). Cox-2 inhibitor use was associated with reduced risk of all CVE (RR 0.48, 95\% CI 0.33-0.70, $I^{2}=0 \%$ ). Non-selective NSAIDs were not associated with any increased/decreased risk of any CVE. Metaanalysis of three studies of MI did not show a significant association with TNFi (RR 0.88, 95\% CI $0.57-1.35, I^{2}=76 \%$ ).

Conclusions: In this meta-analysis of non-randomized studies, NSAID users as a whole and users of non-selective NSAIDs did not seem to have a higher risk of any CVE. Limited data suggest a lower risk of composite CVE outcome with Cox-2 inhibitors, unlike the increased risk reported in the general population. No significant association between TNFi and MI was observed. The certainty in evidence was very 
low due to all studies being observational. More studies are needed to study the association between TNFi use and CVE in general to evaluate a possible protective role in AS.

Keywords: Ankylosing Cardiovascular; NSAIDs; TNF inhibitors

\section{Key Summary Points}

Why carry out this study?

Non-steroidal anti-inflammatory drugs (NSAIDs) and tumor necrosis factor inhibitors (TNFi) are the most common therapies used in ankylosing spondylitis (AS); however, their associated long-term effects on cardiovascular risk are unclear.

A systematic review and meta-analysis were conducted to synthesize the evidence regarding the long-term cardiovascular safety of NSAIDs and TNFi in AS.

\section{What was learned from the study?}

NSAID users as a whole and users of nonselective NSAIDs did not seem to have a higher risk of any cardiovascular events (CVE).

More data are needed on the risk of Cox-2 inhibitors in AS patients. Limited data suggest lower risk of composite CVE outcome, unlike their use in the general population.

No significant association between TNFi and myocardial infarction (MI) was observed in the limited number of studies found. More studies are needed to study the association between TNFi use and CVE in general to evaluate a possible protective role in AS.

\section{DIGITAL FEATURES}

This article is published with digital features, including summary slide, to facilitate understanding of the article. To view digital features for this article go to https://doi.org/10.6084/ m9.figshare.13095602.

\section{INTRODUCTION}

Cardiovascular events (CVE) are higher in ankylosing spondylitis (AS) than the general population and are associated with higher mortality [1]. AS patients have a significantly higher risk of myocardial infarction [MI] (odds ratio [OR] 1.60) and stroke (OR 1.50) than the general population [2], comparable to the risk noted for RA patients (OR 1.63 compared to the general population) [3]. Similarly, the overall increase in mortality in AS observed (1.5 times higher than the general population) is attributed largely to CVE $[4,5]$. Significantly higher risk of vascular death, cerebrovascular, and cardiovascular (CV) death was observed in a study from Ontario [6]. In the hospital setting as well, vascular disease has been reported as the most frequent cause of death in AS patients [5]. The higher CV risk in AS has been largely attributed to accelerated atherosclerosis and endothelial dysfunction in the background of inflammation [7]. CVE risk factors, such as hypertension [8] and metabolic syndrome [2], also have a higher prevalence in AS.

Therapies targeted at controlling inflammation may potentially reduce $\mathrm{CV}$ risk, as seen with tumor necrosis factor inhibitors (TNFi) in RA [9]. NSAIDs and TNFi are the most common therapies used in AS. While NSAIDs are known to be associated with an increased risk of CVE in the general population and RA patients $[9,10]$, whether the anti-inflammatory effects of NSAIDs reduce or modify CVE risk in AS is not clear. Prior studies on $\mathrm{CV}$ safety have been performed mostly in RA and osteoarthritis, and in patients with colorectal carcinoma [11-13]. In the context of AS, this question is even more important, as NSAIDs are the first-line therapy per American College of Rheumatology/ Spondylitis Association of America/Spondyloarthritis Research and Treatment Network guidelines [14]. In AS, NSAIDs are often used long term and in a continuous fashion, unlike their use in other forms of inflammatory arthritis, where they are used at times of flare 
[14]. Moreover, differences in the risk of CVE with different types of NSAIDs have been well documented [12, 15]. The degree of Cox-2 inhibition with NSAIDs is hypothesized to play a role. The anti-inflammatory and analgesic effects of NSAIDs are mediated through Cox-2 inhibition, which also increases thromboxaneinduced vasoconstriction and platelet activation, leading to hypertension and net-prothrombotic effect, respectively. Work in RA has shown that TNFi are associated with reduced risk of CVE risk likely secondary to reduced inflammatory burden [9]. Whether the same holds true for AS is unclear. Some studies demonstrate a beneficial effect of TNFi on the lipid profile, subclinical atherosclerosis, and arterial stiffness in AS [16-18]. Ascertaining if the changes in these preclinical CV risk factors translate to clinically meaningful $\mathrm{CV}$ benefit is an unmet need.

We aimed to perform a systematic review and meta-analysis to determine the association of therapies used for AS, such as NSAIDs and TNFi, with CVE in AS.

\section{METHODS}

\section{Search Strategy and Study Selection}

A comprehensive search of several databases from inception to May 29, 2020 was conducted. The databases included Ovid Medline In-Process and Other Non-Indexed Citations, Ovid MEDLINE, Ovid EMBASE, Ovid Cochrane Central Register of Controlled Trials, Ovid Cochrane Database of Systematic Reviews, and Scopus. ACR and EULAR abstracts (without full-text publication) indexed in MEDLINE were included as well. The search strategy was designed and conducted by a medical reference librarian with input from the principal investigator (Supplementary File 1). No language restrictions were made.

We included all original reports fulfilling the following criteria:

1. Adults ( $\geq 18$ years) with AS.
2. Participants were treated with NSAIDs, oral small molecules or biologics, and had a control group (with no drug of interest).

3. Outcomes of interest: all CVE, acute coronary syndrome/ischemic heart disease (ACS/IHD), cerebrovascular accident (CVA), congestive heart failure (CHF), and the composite outcome of major adverse cardiac events (MACE; defined as acute coronary syndrome, cerebrovascular accident/ stroke, and heart failure) were reported with a particular therapy and compared to placebo or a group without the therapy of interest.

4. Duration of follow-up at least 1 year.

While cohort and case-control studies were included, case series, case reports, and non-human studies were excluded. Studies reporting data on CV risk factors (e.g., hyperlipidemia, hypertension) and subclinical or surrogate markers of atherosclerosis (e.g., arterial stiffness or intima thickness) were also excluded. The effect of combination therapy was beyond the scope of this study.

The Preferred Reporting Items for Systematic Reviews and Meta-Analyses (PRISMA) statement for reporting systematic reviews was followed (Fig. 1) [19]. Two authors (PK and RS) screened abstracts for eligibility, retrieved full texts, and excluded irrelevant articles. The inter-rater agreement was very good (kappa statistic 0.92, $95 \%$ CI 0.89 to 0.98). Disagreements were resolved by discussion about eligibility. Bibliographies belonging to included studies, reviews, and relevant articles were screened for additional studies. Duplicate publications were avoided: full-text articles were given preference over abstracts, and when multiple studies from the same dataset were available, we included only the latest study or the report with results from the largest dataset. For example, we included data from Tsai et al. [20], in which data from the entire database was included in the main analysis, and did not include the publication from Wu et al. [21], as it included only a sample from the database (both studies used Taiwan National Health Insurance database). 


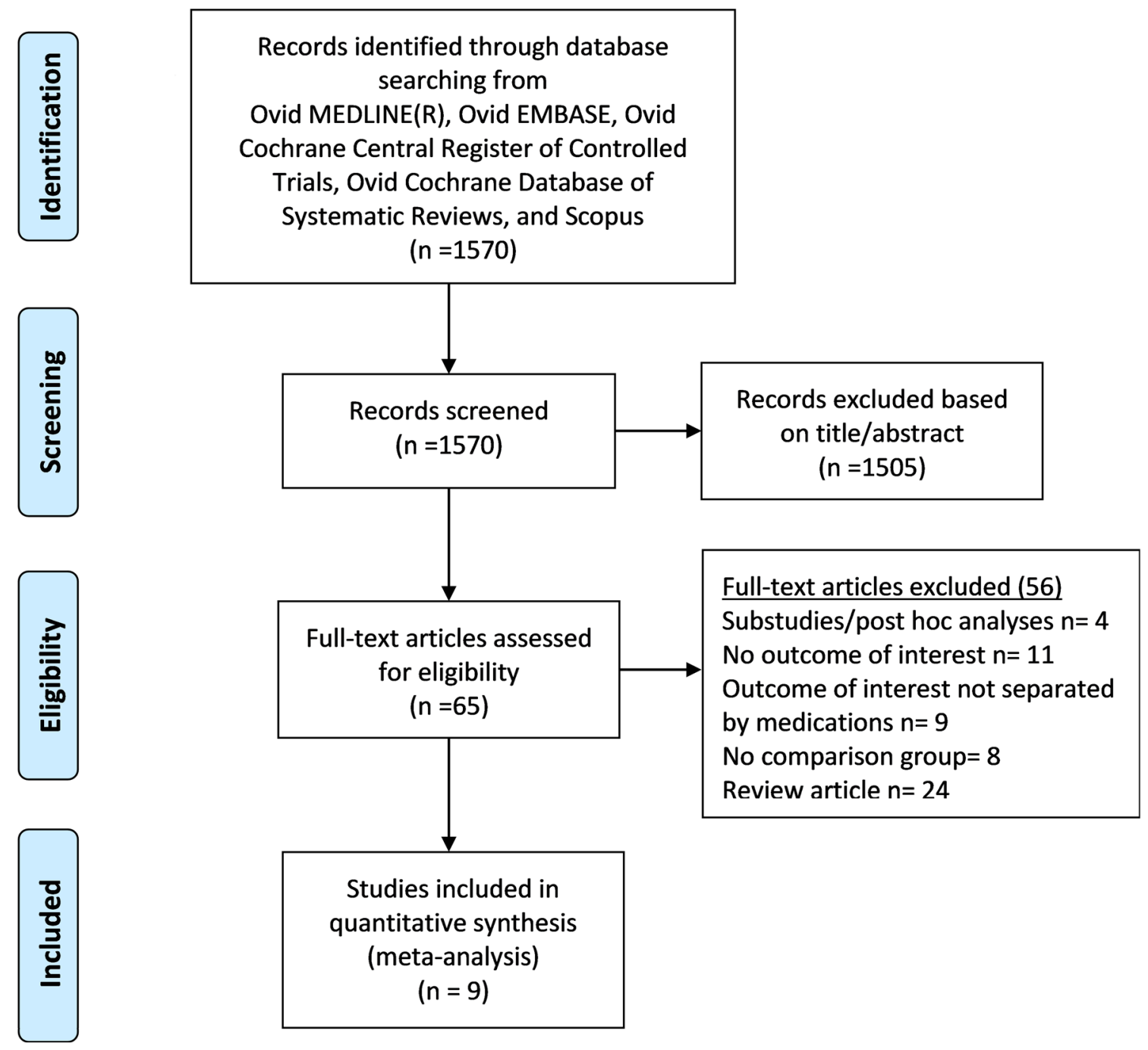

Fig. 1 Flow chart describing systematic search and study selection process

\section{Data Extraction and Risk of Bias Assessment}

Relevant data were extracted by PK, and checked by RS. Data for only AS patients were considered for studies providing $\mathrm{CV}$ outcomes on multiple diseases or spondyloarthritis (SpA) as a whole $[22,23]$. Where no data were reported separately for the subset of patients with AS, the authors were contacted for additional data. If no specific data on AS or CVE could be obtained, the study was excluded [24]. When data at multiple time points were provided, data at the last date of follow-up in the study were used in analyses [20].
Studies were independently evaluated by two reviewers (PK and RS) for the risk of bias [25]. The New-Castle Ottawa scale was used for case-control and cohort studies (Supplementary File 2) [26]. Due to the limitation of tools assessing observational studies [27], the certainty in the evidence was evaluated using the GRADE approach (Grading of Recommendations, Assessment, Development and Evaluation) methodology [28]. Publication bias was assessed visually using funnel plots. Betweenstudy heterogeneity was assessed using $I^{2}$ statistics (i.e., $I^{2}<30 \%$, low heterogeneity, $30-60 \%$, moderate, and $>60 \%$, high) [29]. 


\section{Outcomes}

The main outcome of interest was the association between treatment and all CVE. Secondary outcomes included MI, stroke, congestive heart failure (CHF), and the composite outcome of major adverse cardiac events (MACE).

\section{Statistical Analysis}

Data extracted from the studies were combined for meta-analysis using Review Manager (RevMan) version 5.3. For studies reporting only incident outcomes, RR were calculated. Rate ratios were calculated if person-years of followup were reported. Reported ORs and hazard ratios were converted to risk ratios (RR) using validated statistical formulae $(30,31)$. RR were calculated using relative to the AS group with no therapy of interest if the study reported RRs with a different control group [22, 32]. Studyspecific RR were pooled using a random effects model (DerSimonian and Laird) [33]. To maintain independence, data from the same administrative data from different studies were included in only separate meta-analyses. For example, data from Tsai [20] and Wu et al. [21] (both using the Taiwan National Health Insurance database) were included only in separate meta-analyses.

\section{Compliance with Ethics Guidelines}

This article is based on secondary analysis of previously conducted and published studies and does not contain any data with human participants or animals performed by any of the authors.

\section{RESULTS}

\section{Characteristics of the Included Studies}

Out of 1570 studies screened, nine non-randomized studies fulfilled our inclusion criteria (all English language): seven studies $(N=28,314)$ and four studies $(N=47,153)$ reported the association of NSAIDs and TNFi with CVE, respectively (two studies reported both drugs) [23, 34] (Fig. 1). No studies on the association of CVE pertaining to IL-17 use were found. Among the included studies, seven were published manuscripts and two were abstracts [34, 35]. Included studies were all observational, mostly retrospective cohort, and case-control studies (Table 1). Only one of the studies was a prospective cohort study [23]. While four of the studies were based on national administrative/ health records $[20,21,23,32]$, the remaining five were based on other administrative or insurance claims databases [15, 22, 34-36].

The median (range) study duration was 15 (4-21) years for NSAIDs and 15 (1-23) years for TNFi. AS and CVE were defined in the included studies by International Classification of Diseases, 9th and 10th Revision, Clinical Modification (ICD-9 and 10-CM) and Read codes (documented by general practitioners in the UK), and electronic medical record review. Most studies reported data separately for different types of NSAIDs (Cox-2 selective and non-selective), except two studies that only reported data on NSAIDs as a group. Only one study each reported data on the risk of CHF and MACE (Supplementary File 3). As for the association of CVE with TNFi in AS, only one study reported a cumulative CVE data [23]; and three other studies reported MI and ischemic heart disease events [34-36].

No studies on the CV effects of other biologic agents such as the interleukin (IL)-17A and Janus Kinase inhibitors (JAKi) on AS were found in our systematic review.

\section{All Cardiovascular Events}

In NSAID users as a whole compared to no NSAIDs, no increased risk of CVE was noted (RR $0.96,95 \%$ CI $0.51-1.81, I^{2}=95 \%$ ); Cox-2 inhibitor use was associated with significantly reduced risk of all CVE (RR 0.43, 95\% CI $0.26-0.71, I^{2}=0 \%$ ), but non-selective NSAIDs did not show a significant association (RR 0.93, 95\% CI 0.41-2.11, $I^{2}=81 \%$ ) (Fig. 2). There was only one study reporting all CVE with TNFi, which showed an increased risk (RR 1.60, 95\% CI 1.05-2.41). 


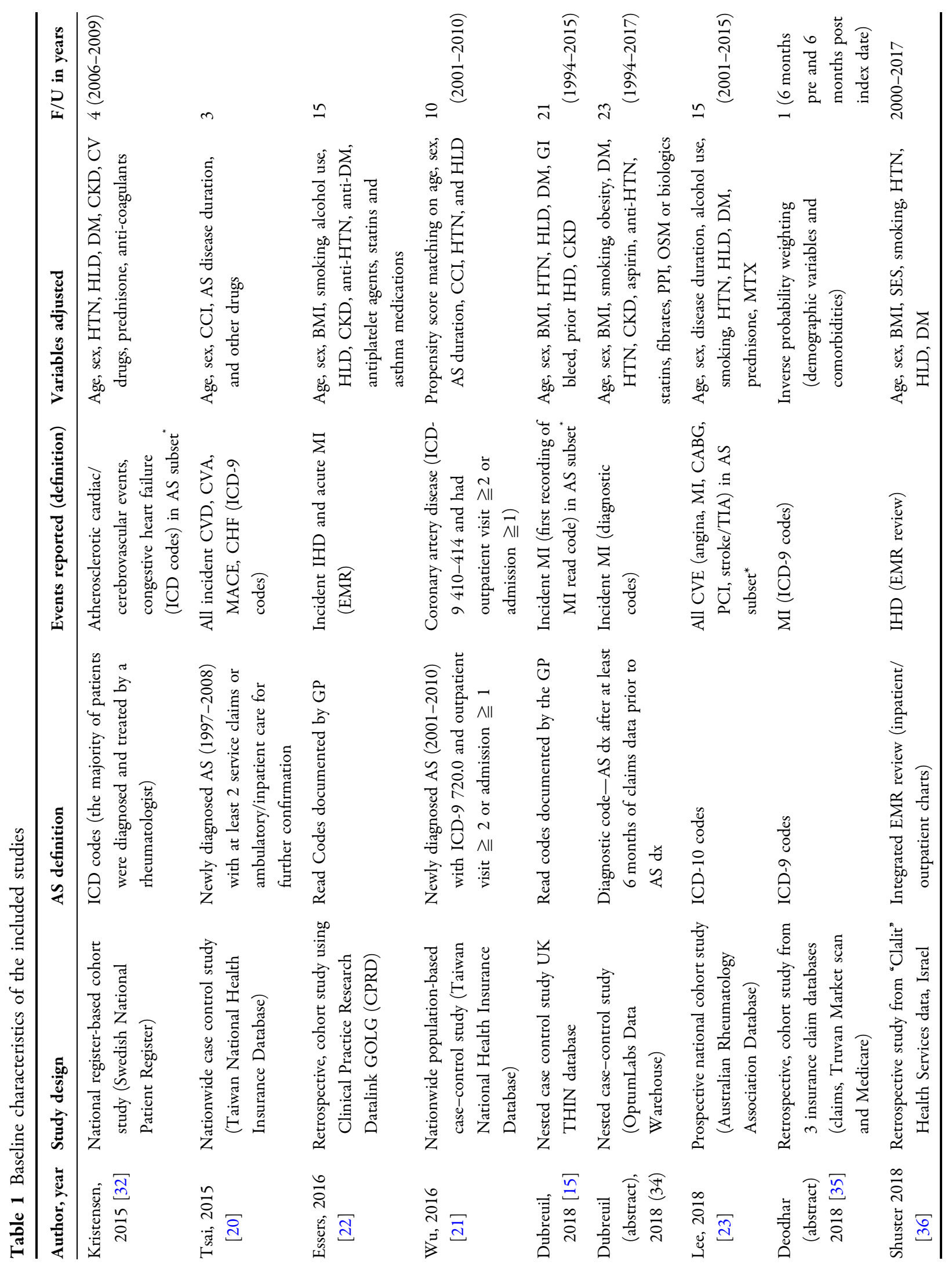




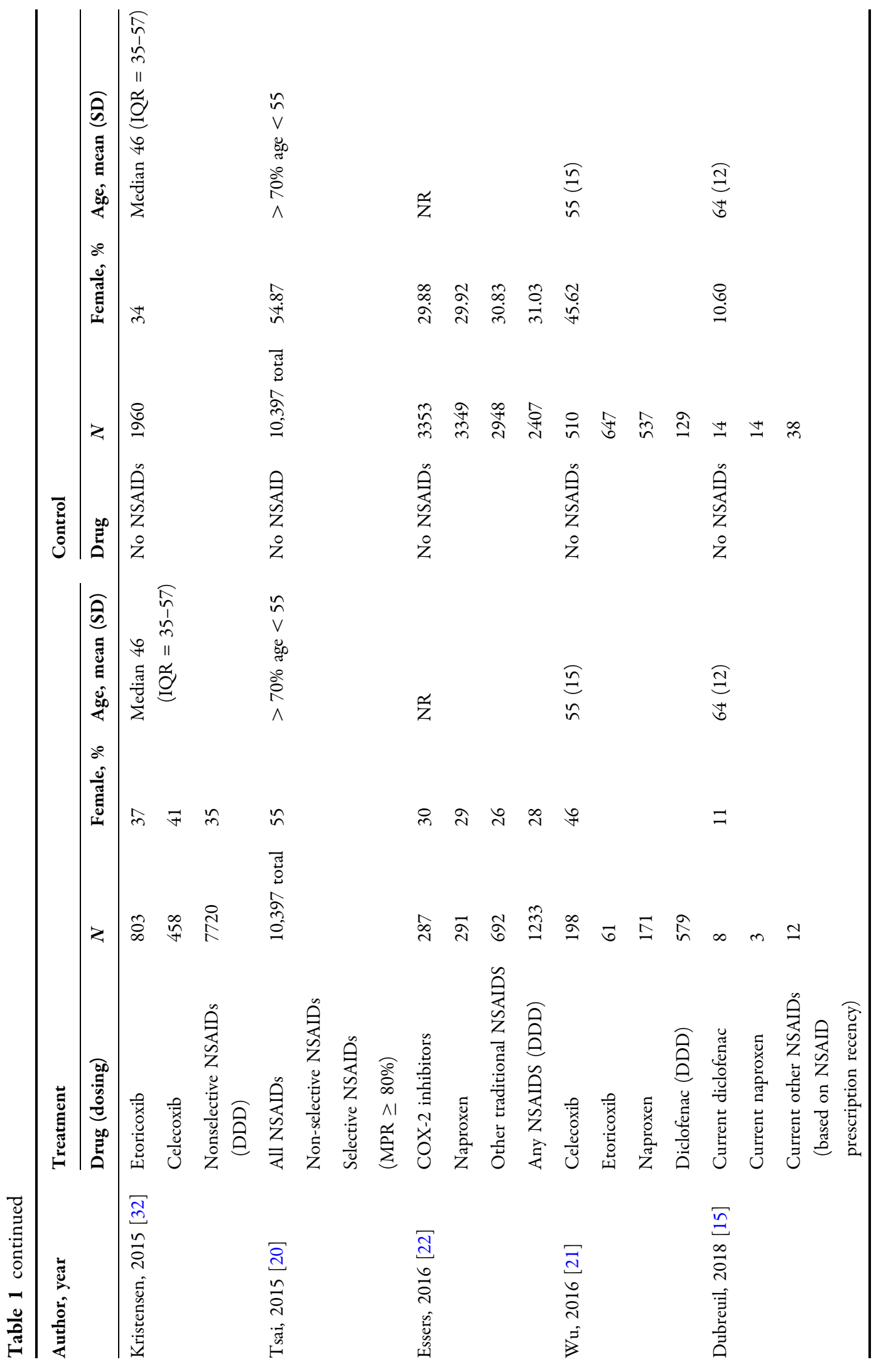




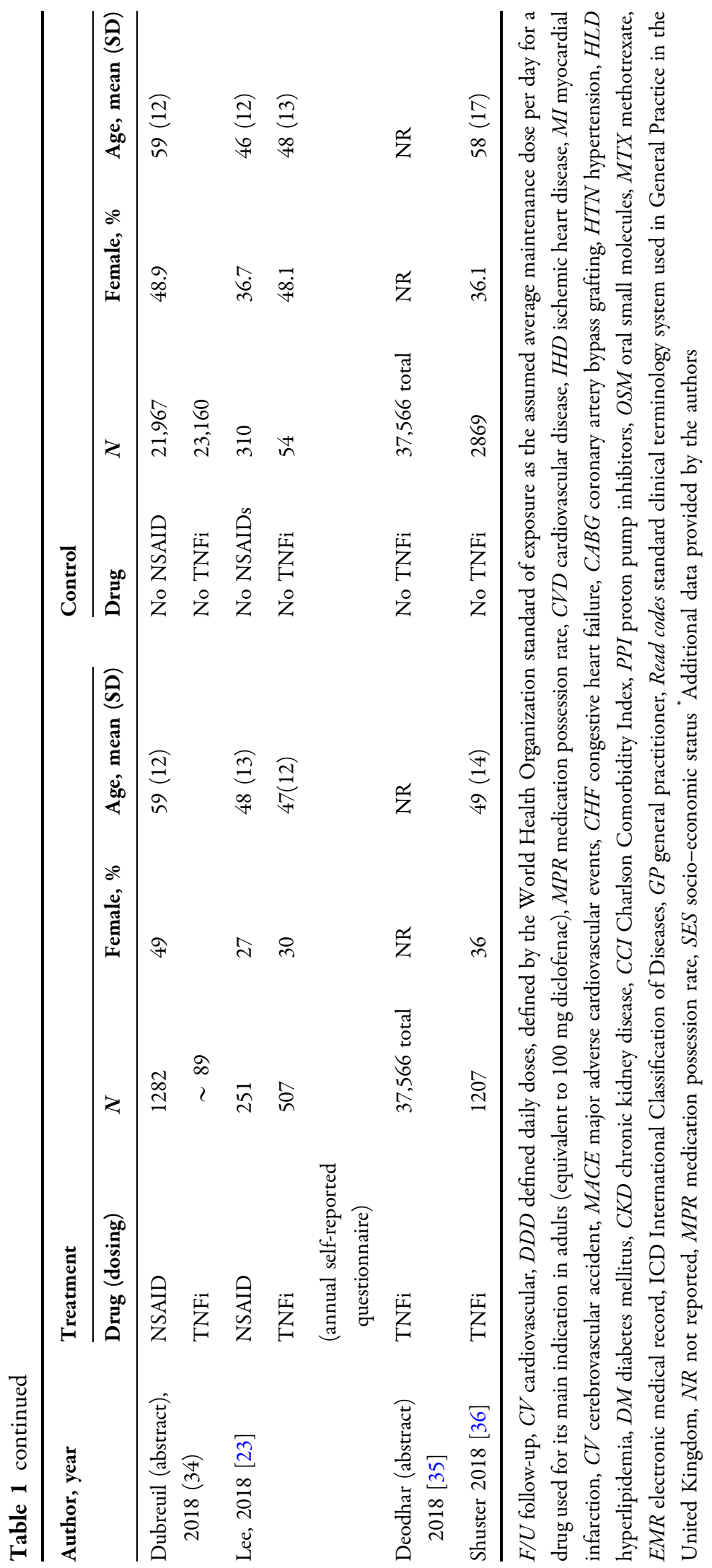


A. All CVE- all NSAIDS

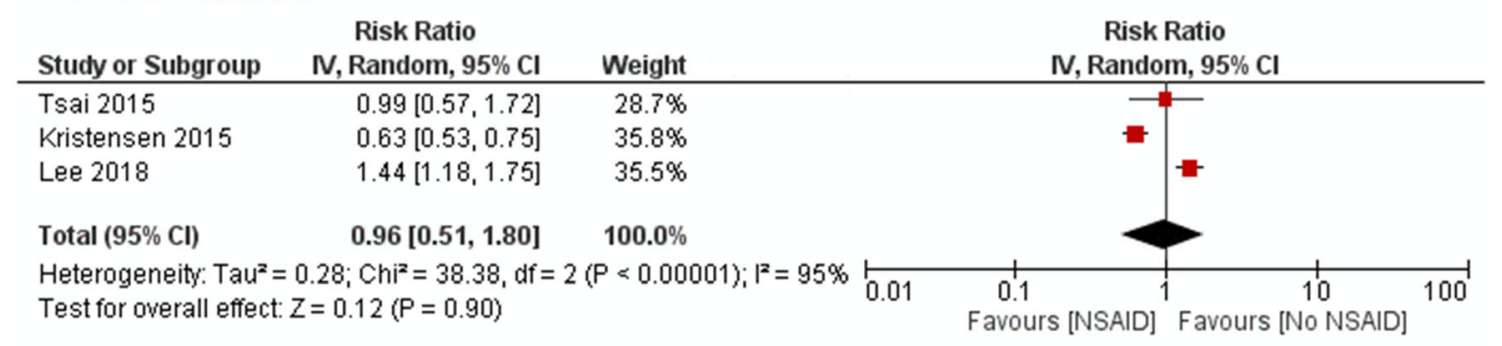

\section{B. All CVE- non selective NSAIDs}

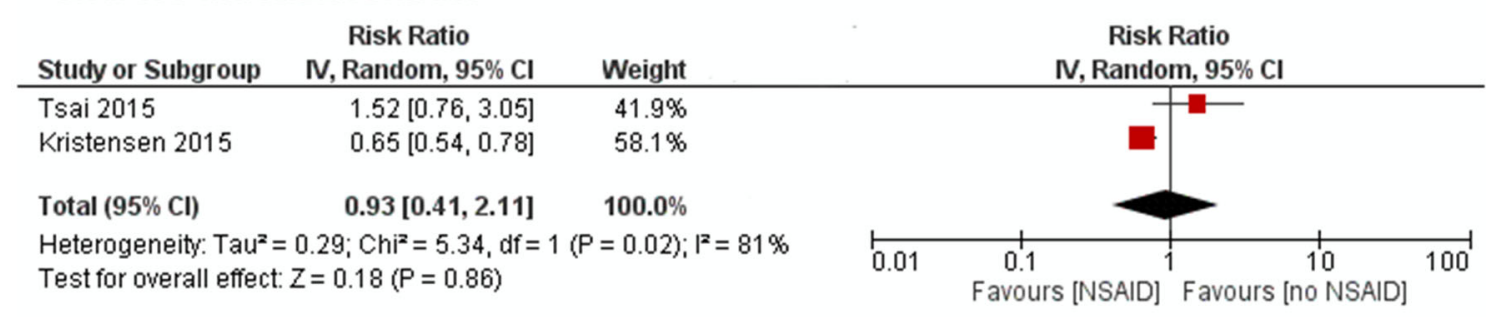

\section{All CVE- Cox-2 inhibitors}

\begin{tabular}{|c|c|c|c|c|c|c|}
\hline Study or Subgroup & $\begin{array}{c}\text { Risk Ratio } \\
\text { IV, Random, } 95 \% \mathrm{Cl}\end{array}$ & Weight & \multicolumn{4}{|c|}{$\begin{array}{c}\text { Risk Ratio } \\
\text { IV, Random, } 95 \% \mathrm{Cl}\end{array}$} \\
\hline Kristensen 2015 & $0.44[0.25,0.75]$ & $85.8 \%$ & & -5 & & \\
\hline Tsai 2015 & $0.37[0.10,1.43]$ & $14.2 \%$ & & & & \\
\hline Total $(95 \% \mathrm{Cl})$ & $0.43[0.26,0.71]$ & $100.0 \%$ & & & & \\
\hline $\begin{array}{l}\text { Heterogeneity: Tau² } \\
\text { Test for overall effec }\end{array}$ & $\begin{array}{l}0.00 ; C^{2}=0.05, d f= \\
=3.29(P=0.0010)\end{array}$ & $=0.83) ; 1^{2}=0 \%$ & 0.01 & $\begin{array}{c}0.1 \\
\text { Favours [NSAID] }\end{array}$ & $\begin{array}{cc}10 \\
\text { Favours [no NSAID] }\end{array}$ & 100 \\
\hline
\end{tabular}

\section{All CVE-TNFi}

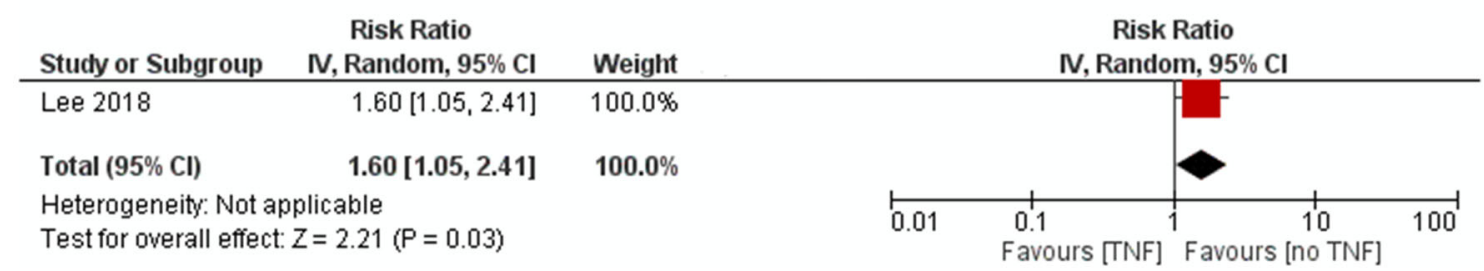

Fig. 2 Forest plot on the risk of all cardiovascular events (CVE) in ankylosing spondylitis patients with a all NSAIDs, b non-selective NSAIDs, c Cox-2 inhibitors, $\mathbf{d}$ tumor necrosis factor inhibitors (TNFi)

\section{Acute Coronary Syndrome/Ischemic Heart Disease (ACS/IHD)}

Meta-analysis of five studies showed no significant effect of NSAIDs as a group (RR 1.11, 95\% CI $0.81-1.53, I^{2}=80 \%$ ), non-selective NSAIDs (RR 1.18, 95\% CI 0.83-1.69, $I^{2}=83 \%$ ), or Cox-2 inhibitors (RR 0.81, 95\% CI 0.41-1.60, $I^{2}=69 \%$ ) compared to no NSAIDs on ACS/IHD (Fig. 3). To ascertain if the $\mathrm{CV}$ risk was different among the different non-selective NSAIDs, we separately looked at the risk of CVE in naproxen and diclofenac users. There was no statistically significant difference in the risk of CVE in those on naproxen (RR 0.78, 95\% CI 0.29-2.10, $I^{2}=63 \%$ ) or diclofenac (RR 1.43, 95\% CI 0.91-2.26, $\left.I^{2}=36 \%\right)$ compared to those not on NSAIDs (Fig. 5). Meta-analysis of three studies of myocardial infarction (MI) specifically did not show a significant association with TNFi compared to those not on TNFi (RR 0.89, 95\% CI $0.59-1.34, I^{2}=78 \%$ ). 


\section{A. ACS/IHD- all NSAIDs}

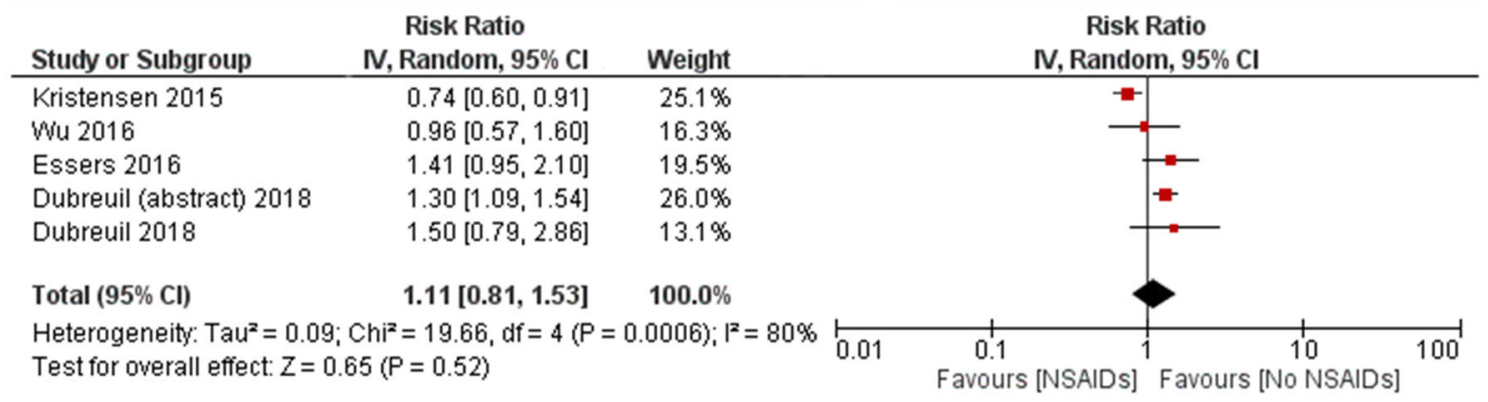

\section{B. ACS/IHD- non selective NSAIDs}

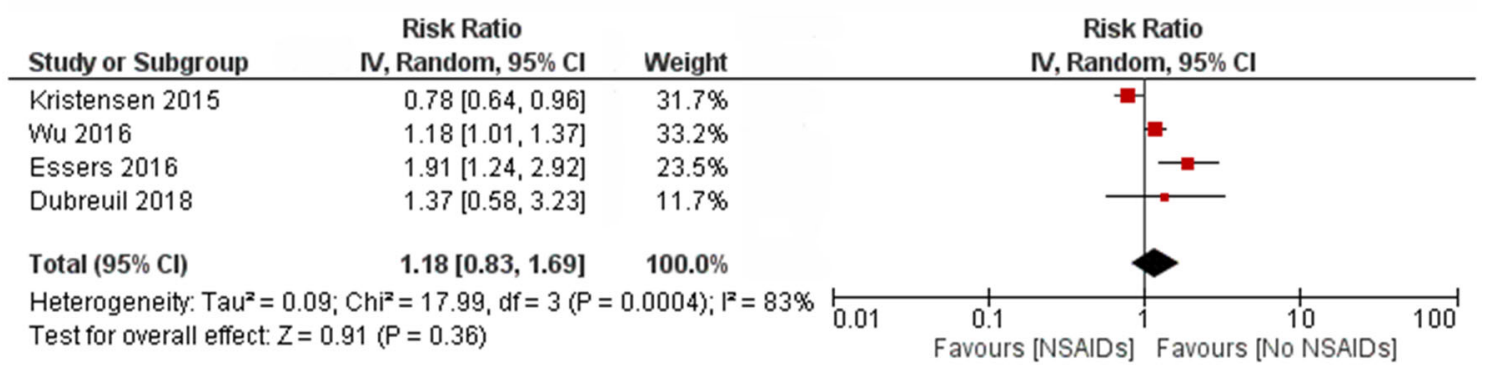

\section{ACS/IHD- Cox-2 inhibitors}

\begin{tabular}{|c|c|c|c|c|c|c|}
\hline Study or Subgroup & $\begin{array}{c}\text { Risk Ratio } \\
\text { IV, Random, } 95 \% \mathrm{Cl}\end{array}$ & Weight & \multicolumn{4}{|c|}{$\begin{array}{c}\text { Risk Ratio } \\
\text { I, Random, } 95 \% \mathrm{Cl} \\
\end{array}$} \\
\hline Kristensen 2015 & $0.30[0.13,0.70]$ & $23.4 \%$ & & $\Longrightarrow$ & & \\
\hline Essers 2016 & $1.27[0.65,2.47]$ & $27.5 \%$ & & & & \\
\hline Wu 2016 & $0.69[0.41,1.16]$ & $30.6 \%$ & & & & \\
\hline Dubreuil 2018 & $1.94[0.64,5.92]$ & $18.5 \%$ & & & & \\
\hline Total $(95 \% \mathrm{Cl})$ & $0.81[0.41,1.60]$ & $100.0 \%$ & & & & \\
\hline \multicolumn{3}{|c|}{$\begin{array}{l}\text { Heterogeneity: } \text { Tau }^{2}=0.32 ; \mathrm{Chi}^{2}=9.77, \mathrm{df}=3(\mathrm{P}=0.02) ; \mathrm{I}^{2}=69 \% \\
\text { Test for overall effect: } Z=0.60(P=0.55)\end{array}$} & 0.01 & $\begin{array}{c}0.1 \\
\text { Favours [NSAIDs] }\end{array}$ & $\begin{array}{c}10 \\
10 \\
\text { Favours [NO NSAIDs] }\end{array}$ & $\overrightarrow{100}$ \\
\hline
\end{tabular}

\section{ACS/IHD- TNFi}

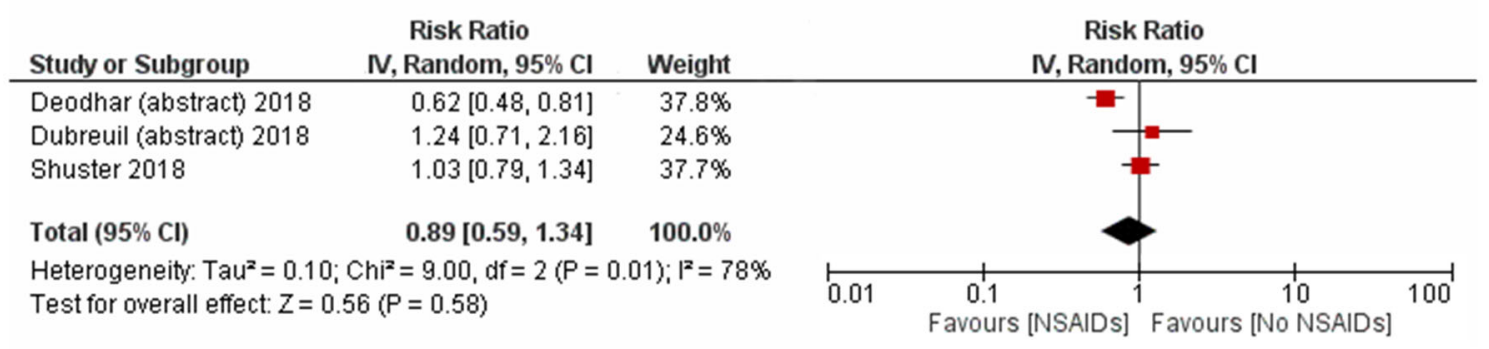

Fig. 3 Forest plot on the risk of acute coronary syndrome/ischemic heart disease (ACS/IHD) with a all NSAIDs, $\mathbf{b}$ nonselective NSAIDs, $\mathbf{c}$ Cox-2 inhibitors, $\mathbf{d}$ tumor necrosis factor inhibitors (TNFi)

\section{Cerebrovascular Events (CVA)}

The risk of cerebrovascular accident (CVA) was significantly lower (RR 0.52, 95\% CI 0.37-0.73, $\left.I^{2}=6 \%\right)$ for NSAIDs as a whole, but did not reach significance individually for Cox 2-inhibitors (RR $0.59,95 \%$ CI $0.33-1.08, I^{2}=0 \%$ ) or non-selective NSAIDs (RR $0.65,95 \%$ CI 0.26-1.64, $I^{2}=95 \%$ ) (Fig. 4). 
A. CVA- all NSAIDs

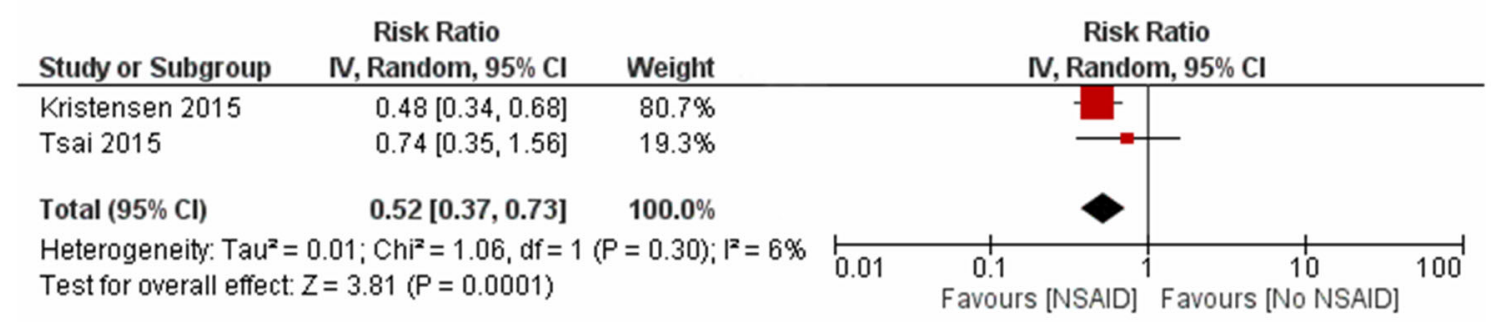

\section{B. CVA- non selective NSAIDs}

\begin{tabular}{|c|c|c|c|c|c|}
\hline Study or Subgroup & $\begin{array}{c}\text { Risk Ratio } \\
\text { IV, Random, } 95 \% \mathrm{Cl}\end{array}$ & Weight & \multicolumn{3}{|c|}{$\begin{array}{c}\text { Risk Ratio } \\
\text { IV, Random, } 95 \% \mathrm{Cl}\end{array}$} \\
\hline Kristensen 2015 & $0.45[0.31,0.64]$ & $60.5 \%$ & & & \\
\hline Tsai 2015 & $1.17[0.46,2.98]$ & $39.5 \%$ & & & \\
\hline Total (95\% Cl) & $0.65[0.26,1.64]$ & $100.0 \%$ & & & \\
\hline \multicolumn{3}{|c|}{$\begin{array}{l}\text { Heterogeneity: } \text { Tau }^{2}=0.33 ; \mathrm{Chi}^{2}=3.54, \mathrm{df}=1(\mathrm{P}=0.06) ; \mathrm{I}^{2}=72 \% \stackrel{ }{0.01} \\
\text { Test for overall effect: } Z=0.90(\mathrm{P}=0.37)\end{array}$} & $\begin{array}{c}1 \\
0.1 \\
\text { Favours [NSAID] }\end{array}$ & $\begin{array}{c}10 \\
\text { Favours [no NSAID] }\end{array}$ & $\overrightarrow{100}$ \\
\hline
\end{tabular}

\section{CVA-Cox-2 inhibitors}

\begin{tabular}{|c|c|c|c|c|c|c|}
\hline Study or Subgroup & $\begin{array}{c}\text { Risk Ratio } \\
\text { IV, Random, } 95 \% \mathrm{Cl}\end{array}$ & Weight & \multicolumn{4}{|c|}{$\begin{array}{c}\text { Risk Ratio } \\
\text { IV, Random, 95\% Cl } \\
\end{array}$} \\
\hline Tsai 2015 & $0.37[0.03,4.95]$ & $5.3 \%$ & & & & \\
\hline Kristensen 2015 & $0.61[0.33,1.13]$ & $94.7 \%$ & & & & \\
\hline Total $(95 \% \mathrm{Cl})$ & $0.59[0.33,1.08]$ & $100.0 \%$ & & & & \\
\hline $\begin{array}{l}\text { Heterogeneity: } \operatorname{Tau}^{2}= \\
\text { Test for overall effect }\end{array}$ & $\begin{array}{l}.00 ; C^{2}=0.14, d f=1 \\
=1.70(P=0.09)\end{array}$ & $=0.71) ; I^{2}=0 \%$ & 0.01 & $\begin{array}{c}0.1 \\
\text { Favours [NSAID] }\end{array}$ & $\begin{array}{c}10 \\
\text { Favours [no NSAID] }\end{array}$ & 100 \\
\hline
\end{tabular}

Fig. 4 Forest plot on the risk of cerebrovascular accidents (CVA) with a all NSAIDs, $\mathbf{b}$ non-selective NSAIDs, $\mathbf{c}$ Cox-2 inhibitors

\section{Other Cardiac Outcomes}

Only one study reported risk of CHF with NSAIDs; the study showed a lower risk with NSAIDs as a group (RR 0.28, 95\% CI 0.20-0.37), and individually with Cox-2 inhibitors (RR 0.27, 95\% CI $0.10-0.60)$ and non-selective NSAIDs (RR 0.28, 95\% CI 0.20-0.37). Similarly, there was no difference in MACE with NSAIDs as a group (RR $0.52,95 \%$ CI $0.13-2.10)$, or with Cox-2 inhibitors (RR 1.43, 95\% CI 0.08-25.09) or non-selective NSAIDs (RR 1.38, 95\% CI $0.23-8.45)$ in the only study reporting this specific outcome.

\section{Risk of Bias}

Assessment of overall risk of bias for the included studies is summarized in supplementary file
2. All the included studies were judged to have a low risk of bias as per the New-Castle Ottawa scale for observational studies [26]. All the included studies were observational, therefore the certainty in evidence evaluated using the GRADE approach methodology was low to very low [28]. Publication bias was unable to be assessed accurately as we had fewer than ten eligible studies (Supplementary file 4).

\section{DISCUSSION}

This systematic review, including nine nonrandomized studies, found no increased risk of any CVE with NSAIDs as a whole and lower risk with NSAIDs as a group for CVA in the limited number of studies found. Limited data suggested a possible lower risk of composite outcome of CVE with Cox-2 inhibitors. No 
significant association between TNFi and MI was observed, and studies on other CV outcomes with TNFi were limited.

While long-term NSAIDs use has been associated with increased risk of CVE in the general population [12], we found a limited number of studies on the effects of NSAIDs on the CVE risk in AS where they are used as first-line therapy. Studies in inflammatory polyarthritis and RA suggest that the effect of NSAIDs on CV outcomes might be different for inflammatory arthritis. The UK Norfolk Arthritis Register (NOAR) data for an inception cohort of inflammatory polyarthritis and the Danish RA cohort both did not show higher CVE or allcause mortality with NSAIDs [37, 38]. Our review found similar results in AS patients, with no increased risk of any CVE (composite CVE outcome, ACS/IHD, or CVA) with NSAIDs as a whole. In fact, a significantly lower risk of CVA seen was seen with NSAIDs as a whole. Similarly, non-selective NSAIDs as a group were not found to have increased risk of a composite CVE outcome, ACS/IHD, or CVA. Some prior studies have shown that the risk within individual nonselective NSAIDs might differ as well [15]. Metaanalysis of the included studies, however, did not find any difference in the risk of CVE with naproxen or diclofenac (Fig. 5). While diclofenac was noted to be associated with a higher risk of ACS in data from the UK THIN database, data from Taiwan was reassuring $[15,21]$. Although the pooled estimate was numerically higher in diclofenac users, it was not statistically significant.

Similarly, data regarding the risk of CVE with selective Cox-2 inhibitors were also limited. Pooled data from two of the included studies $[20,32]$ showed a lower risk of the composite CVE outcome with Cox-2 inhibitors in AS. With respect to the risk of ACS/IHD, studies showed discordant results with Cox-2 inhibitors in AS with no overall increased risk (Fig. 3). The difference in study designs could also have led to different results: two cohort studies and one case-control study. Even among the two cohort studies from the UK and Sweden, respectively, Essers et al. [22] reported incidence rates (excluding patients with pre-existing ACS/IHD) and Kristensen et al. [32] reported RRs adjusted for prior CVE (did not exclude patients with preexisting ACS/IHD). Sensitivity analysis excluding the case-control study by $\mathrm{Wu}$ et al. did not change the results. As all the studies were from national administrative databases, AS-specific characteristics such as disease activity were not available. Differences in disease characteristics could have further accounted for the different

\section{A. ACS/IHD - Naproxen}

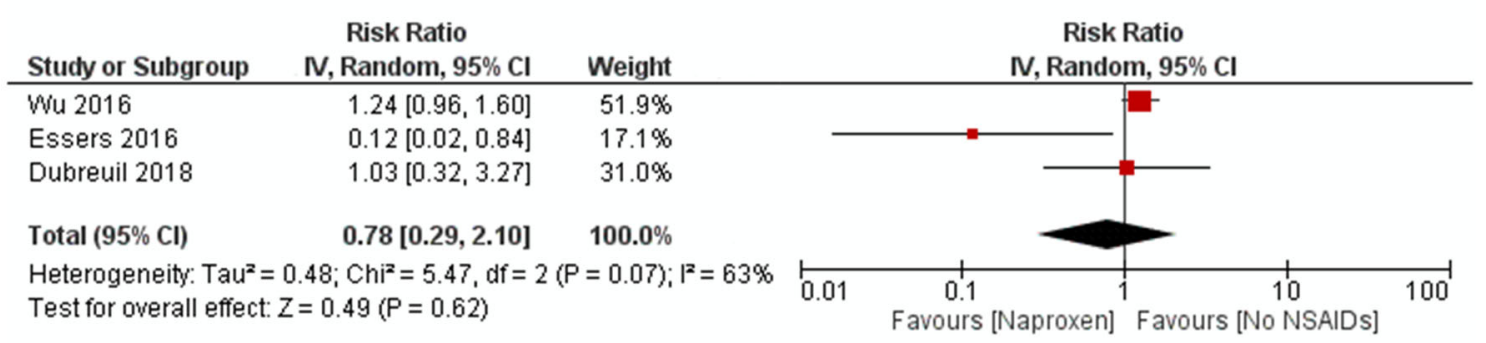

\section{B. ACS/IHD - Diclofenac}

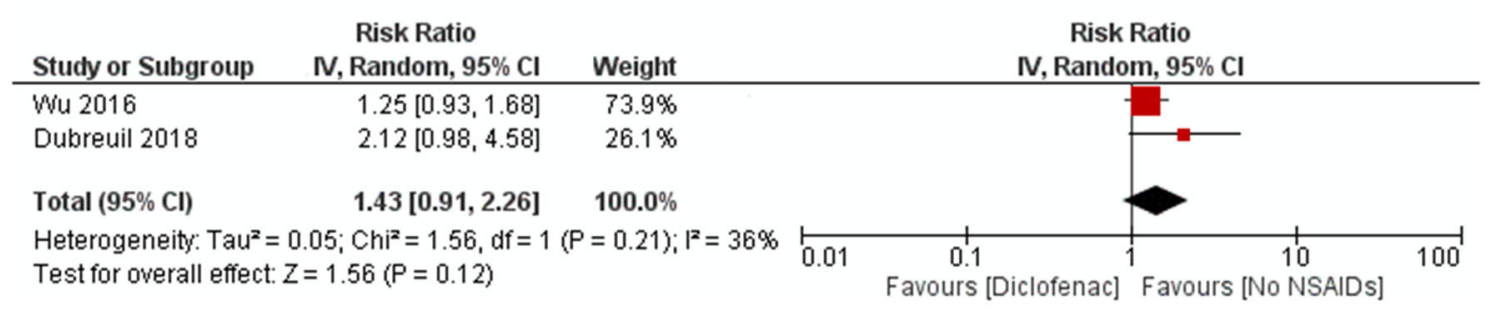

Fig. 5 Forest plot on the risk of ACS/IHD with specific non-selective NSAIDs a naproxen and $\mathbf{b}$ diclofenac 
results. Nonetheless, Cox-2 was associated with a lower risk for different $\mathrm{CV}$ outcomes studied in the pooled analyses of a limited number of studies.

The differential effects of NSAIDs have been well documented in the literature, and are believed to be related to the degree of Cox-2 selectivity. Increased in CVE with the selective Cox-2 inhibitor, rofecoxib lead to its withdrawal from the market [39]. Similarly, celecoxib was noted to be associated with a doserelated increased risk of CVE (composite endpoint of $\mathrm{CV}$ death, MI, stroke, and heart failure) in colon cancer patients [13]. In the more recent PRECISION trial, no increase in CVE risk with celecoxib was seen as compared to other traditional NSAIDs in a subgroup of patients with RA. This trial, however, had a low adherence rate and a relatively low dose of Cox- 2 inhibitors [11]. The beneficial effect of Cox-2 inhibitors seen in our meta-analysis of the included studies might be specific to AS, as Cox-2 inhibitors have also been shown to be associated with lower radiographic progression in AS patients when used in conjunction with TNFi, as opposed to traditional NSAIDs [40]. The reason for the noted differential benefit of Cox-2 inhibitors in AS is not clear. However, the effect of confounding cannot be ruled out, especially given that all the included studies were observational. For example, clinicians may avoid Cox-2 inhibitors in patients perceived to have high CV risk (channeling bias), or alternatively patients whose symptoms are controlled on celecoxib at lower doses (200 mg per day) may have milder AS than those who require "high" doses of traditional NSAIDs. While statistical methods may be used to attempt to adjust for such confounding in observational studies, such methods were not used in all of the studies included in this meta-analysis. AS disease duration was adjusted for in few of the included studies [20, 21, 23], however, other disease-related factors such as disease activity were not accounted for. Therefore, the safety of higher doses of Cox-2 inhibitors remains uncertain.

While TNFi are associated with decreased risk of CVE in RA [9], the risk in AS remains unclear. Our review found only limited data on the effects of TNFi on CVE in AS. Studies have shown a beneficial effect of TNFi on CV parameters such as lipid profile, atherosclerosis, and CV function. Van Eijk et al. showed improvement in lipid profile after 3 months of etanercept therapy in AS patients [16]. Similarly, significantly lower intima-media thickness on carotid sonography was seen in AS patients on TNFi compared to healthy matched controls, and improvement in endothelial function was noted $[17,18]$. Reduction in subclinical myocardial inflammation and improved $\mathrm{CV}$ function was found in cardiac magnetic resonance imaging in RA, AS, and psoriatic arthritis patients on TNFi [41]. More recent studies have also shown that TNFi led to significantly lower complement activation in SpA [42]. However, it is unclear whether these subclinical changes lead to clinically meaningful change in CV outcomes in AS. In the limited number of studies included, no difference was observed in the risk of acute coronary syndrome/ischemic heart disease (ACS/IHD) in AS patients with and without TNFi. While a minimally increased risk of composite CVE was noted with TNFi in the only study reporting this [23], there was no increase in ACS/IHD. These findings support the current guidelines recommending long-term use of NSAIDs and do not show any safety concerns in the limited data for TNFi in AS [14].

This systematic review has several limitations and strengths. The certainty in evidence in all estimates was very low due to the studies being non-randomized. Moreover, there were only a few studies examining some of the $\mathrm{CV}$ outcomes. Heterogeneity was high for some $\mathrm{CV}$ outcomes, which is likely related to different study designs, and different definitions of NSAIDs use and doses in the studies. While the comparator arm was uniformly no NSAIDs (for NSAIDs) and no TNFi (for TNFi), respectively, there were differences in the CV outcome definitions across studies. Subgroup analyses to explore the cause of heterogeneity could not be performed due to the overall low number of studies. Results from the included observational studies might be limited due to confounding by indication as those with a higher risk of CVE such as ischemic heart disease or heart failure are less likely to be treated with NSAIDs. 
However, most studies adjusted for multiple factors including baseline demographic characteristics, traditional CV risk factors, comorbidities, and other medications (Table 1). We note that only a few studies included glucocorticoid use as a potential confounder [23, 32], however we assume that the use of glucocorticoids would be relatively rare, as efficacy in AS is lower compared to other inflammatory arthritides such as RA. Moreover, setting up a randomized controlled trial to study the risk of NSAIDs would require a very large number of patients, as the event rate is low (assuming an annual event rate of approximately $2 \%$ followed for approximately 3 years, a sample size of 20,000 patients would be required). For example, the PRECISION trial in RA included 24,222 patients from 926 centers with a mean follow-up of $34.1 \pm 13.4$ months [11]. Most studies relating to TNFi exposure were cross-sectional, hence the results should be interpreted with caution. While the reported major adverse cardiac events with secukinumab were low in clinical trial and post-marketing surveillance data, controlled data are lacking [43]. We also did not find any studies on the CV effects of IL-17A or JAKi on CVE in AS. Longitudinal analysis of CVE in TNFi and IL-17A trials on AS might provide more data on the association of TNFi with CVE in AS. Similarly, the effect of combined therapy of NSAIDs and biologics on CVE must be explored.

\section{CONCLUSIONS}

This systematic review suggests that NSAID users as a whole and users of non-selective NSAIDs did not seem to have a higher risk of any CVE. Limited data suggest possibly lower risk of composite CVE outcome in AS patients on Cox-2 inhibitors, unlike their use in the general population. These results provide some reassurance for use of NSAIDs in AS. No association between TNFi and MI was observed in a limited number of observational studies.

\section{ACKNOWLEDGEMENTS}

We would like to thank our librarian, Larry Prokop, for help with the extensive search strategy, and Dr. Premarani Sinnathurai (Lee et al. study) [23] and Dr. Lars Erik Kristensen [32] for providing additional data.

Funding. This project was supported by CTSA Grant Number UL1 TR002377 from the National Center for Advancing Translational Science (NCATS) (PK), T32 AR56950 grant from the National Institute of Arthritis and Musculoskeletal and Skin Diseases for the Musculoskeletal Research Training Program (PK), NIH AR0691427 (MD), AR04775 (MD), and T32 GM08685 (PS). Its contents are solely the responsibility of the authors and do not necessarily represent the official views of the NIH. No direct financial support was received for this project. No Rapid Service Fee was received by the journal for the publication of this article.

Authorship. All named authors meet the International Committee of Medical Journal Editors (ICMJE) criteria for authorship for this article, take responsibility for the integrity of the work as a whole, and have given their approval for this version to be published.

Authorship Contributions. PK conceived, designed, and wrote the initial draft of the study; PK, RS, PS participated in the abstraction, analysis, and interpretation of data. DB, CSC, MHM, JMD, KW, RK, and MD analyzed, interpreted, and provided intellectual content, edited subsequent draft, and approved the final article. P.K. is responsible as overall guarantor of the content.

Prior Presentation. This manuscript is based on work that has been previously presented at the Spondyloarthritis Research and Treatment Network (SPARTAN) Annual Meeting in Madison, WI, May 2019, and American College of Rheumatology (ACR) Annual Meeting, Atlanta, November 2019.

Disclosures. John M. Davis III has received consulting fees and/or honoraria from AbbVie 
and Sanofi-Genzyme (less than $\$ 10,000$ each) and research support from Pfizer, and is a member of the journal's Editorial Board. Maureen Dubreuil has received consulting fees and/ or honoraria from UCB (less than \$10,000). Paras Karmacharya, Ravi Shahukhal, Cynthia S. Crowson, M. Hassan Murad, Pragya Shrestha, Delamo Bekele, Kerry Wright, and Rikesh Chakradhar have nothing to disclose.

Compliance with Ethics Guidelines. This article is based on secondary analysis of previously conducted and published studies and does not contain any data with human participants or animals performed by any of the authors.

Data Availability. All data generated or analyzed are available in this article or the supplementary file.

Open Access. This article is licensed under a Creative Commons Attribution-NonCommercial 4.0 International License, which permits any non-commercial use, sharing, adaptation, distribution and reproduction in any medium or format, as long as you give appropriate credit to the original author(s) and the source, provide a link to the Creative Commons licence, and indicate if changes were made. The images or other third party material in this article are included in the article's Creative Commons licence, unless indicated otherwise in a credit line to the material. If material is not included in the article's Creative Commons licence and your intended use is not permitted by statutory regulation or exceeds the permitted use, you will need to obtain permission directly from the copyright holder. To view a copy of this licence, visit http://creativecommons.org/licenses/by$\mathrm{nc} / 4.0 /$.

\section{REFERENCES}

1. Liew JW, Ramiro S, Gensler LS. Cardiovascular morbidity and mortality in ankylosing spondylitis and psoriatic arthritis. Best Pract Res Clin Rheumatol. 2018;32(3):369-89.
2. Mathieu S, Gossec L, Dougados M, Soubrier M. Cardiovascular profile in ankylosing spondylitis: a systematic review and meta-analysis. Arthritis Care Res. 2011;63(4):557-63.

3. Lévy L, Fautrel B, Barnetche T, Schaeverbeke T. Incidence and risk of fatal myocardial infarction and stroke events in rheumatoid arthritis patients. A systematic review of the literature. Clin Exp Rheumatol. 2008;26(4):673-9.

4. Lehtinen K. Mortality and causes of death in 398 patients admitted to hospital with ankylosing spondylitis. Ann Rheum Dis. 1993;52(3):174-6.

5. Bakland G, Gran JT, Nossent JC. Increased mortality in ankylosing spondylitis is related to disease activity. Ann Rheum Dis. 2011;70(11):1921-5.

6. Haroon NN, Paterson JM, Li P, Inman RD, Haroon N. Patients with ankylosing spondylitis have increased cardiovascular and cerebrovascular mortality: a population-based study. Ann Intern Med. 2015;163(6):409-16.

7. Azevedo VF, Pecoits-Filho R. Atherosclerosis and endothelial dysfunction in patients with ankylosing spondylitis. Rheumatol Int. 2010;30(11): 1411-6.

8. Walsh JA, Song X, Kim G, Park Y. Evaluation of the comorbidity burden in patients with ankylosing spondylitis using a large US administrative claims data set. Clin Rheumatol. 2018;37(7):1869-78.

9. Roubille C, Richer V, Starnino T, McCourt C, McFarlane A, Fleming P, et al. The effects of tumour necrosis factor inhibitors, methotrexate, non-steroidal anti-inflammatory drugs and corticosteroids on cardiovascular events in rheumatoid arthritis, psoriasis and psoriatic arthritis: a systematic review and meta-analysis. Ann Rheum Dis. 2015;74(3): 480-9.

10. Salvo F, Antoniazzi S, Duong M, Molimard M, Bazin F, Fourrier-Réglat A, et al. Cardiovascular events associated with the long-term use of NSAIDs: a review of randomized controlled trials and observational studies. Expert Opin Drug Saf. 2014;13(5): 573-85.

11. Nissen SE, Yeomans ND, Solomon DH, Lüscher TF, Libby P, Husni ME, et al. Cardiovascular safety of celecoxib, naproxen, or ibuprofen for arthritis. N Engl J Med. 2016;375(26):2519-29.

12. Coxib and traditional NSAID Trialists' (CNT) Collaboration, Bhala N, Emberson J, Merhi A, Abramson S, Arber $\mathrm{N}$, et al. Vascular and upper gastrointestinal effects of non-steroidal anti-inflammatory drugs: meta-analyses of individual 
participant data from randomised trials. Lancet Lond Engl. 2013;382(9894):769-79.

13. Solomon SD, McMurray JJV, Pfeffer MA, Wittes J, Fowler R, Finn P, et al. Cardiovascular risk associated with celecoxib in a clinical trial for colorectal adenoma prevention. N Engl J Med. 2005;352(11): 1071-80.

14. Ward MM, Deodhar A, Gensler LS, Dubreuil M, Yu D, Khan MA, et al. Update of the American College of Rheumatology/Spondylitis Association of America/Spondyloarthritis Research and Treatment Network Recommendations for the treatment of ankylosing spondylitis and nonradiographic axial spondyloarthritis. Arthritis Rheumatol Hoboken. 2019;10:1285-99.

15. Dubreuil M, Louie-Gao Q, Peloquin CE, Choi HK, Zhang Y, Neogi T. Risk of myocardial infarction with use of selected non-steroidal anti-inflammatory drugs in patients with spondyloarthritis and osteoarthritis. Ann Rheum Dis. 2018;77(8): 1137-42.

16. van Eijk IC, de Vries MK, Levels JHM, Peters MJL, Huizer EE, Dijkmans BC, et al. Improvement of lipid profile is accompanied by atheroprotective alterations in high-density lipoprotein composition upon tumor necrosis factor blockade: a prospective cohort study in ankylosing spondylitis. Arthritis Rheum. 2009;60(5):1324-30.

17. Zardi EM, Pipita ME, Giorgi C, Lichinchi D, Zardi DM, Afeltra A. Differences in carotid atherosclerosis between patients with ankylosing spondylitis treated with tumor necrosis factor- $\alpha$ antagonists and healthy matched controls. Medicine (Baltimore). 2018;97(27):e11250.

18. Deyab G, Hokstad I, Whist JE, Smastuen MC, Agewall S, Lyberg T, et al. Methotrexate and anti-tumor necrosis factor treatment improves endothelial function in patients with inflammatory arthritis. Arthritis Res Ther. 2017;19(1):232.

19. Beller EM, Glasziou PP, Altman DG, Hopewell S, Bastian H, Chalmers I et al. PRISMA for Abstracts: Reporting Systematic Reviews in Journal and Conference Abstracts. PLoS Med [Internet]. 2013;10(4). Available from: https://www.ncbi.nlm.nih.gov/ pmc/articles/PMC3621753/

20. Tsai W-C, Ou T-T, Yen J-H, Wu C-C, Tung Y-C. Long-term frequent use of non-steroidal anti-inflammatory drugs might protect patients with ankylosing spondylitis from cardiovascular diseases: a nationwide case-control study. PLoS ONE. 2015;10(5):e0126347.

21. Wu L-C, Leong P-Y, Yeo K-J, Li T-Y, Wang Y-H, Chiou J-Y, et al. Celecoxib and sulfasalazine had negative association with coronary artery diseases in patients with ankylosing spondylitis: a nationwide, population-based case-control study. Medicine (Baltimore). 2016;95(36):e4792.

22. Essers I, Stolwijk C, Boonen A, De Bruin ML, Bazelier MT, de Vries F, et al. Ankylosing spondylitis and risk of ischaemic heart disease: a population-based cohort study. Ann Rheum Dis. 2016;75(1):203-9.

23. Lee JL, Sinnathurai P, Buchbinder R, Hill C, Lassere M, March L. Biologics and cardiovascular events in inflammatory arthritis: a prospective national cohort study. Arthritis Res Ther. 2018;20(1):171.

24. Rivière $\mathrm{E}$, Etcheto $\mathrm{A}$, den Bosch FV, der Heijde DV, Landewé R, Dougados M, et al. THU0350 Effect of NSAID consumption on cardiovascular events in spondyloarthritis. Ann Rheum Dis. 2017;76(Suppl 2):336-336.

25. Higgins JP, Green S, editors. Cochrane handbook for systematic reviews of interventions. https:// handbook-5-1.cochrane.org/front_page.htm.

26. Ottawa Hospital Research Institute [Internet] Available from: https://www.ohri.ca/programs/ clinical_epidemiology/oxford.asp. Cited 10 Mar 2019.

27. Losilla J-M, Oliveras I, Marin-Garcia JA, Vives J. Three risk of bias tools lead to opposite conclusions in observational research synthesis. J Clin Epidemiol. 2018;101:61-72.

28. Murad MH. Clinical practice guidelines: a primer on development and dissemination. Mayo Clin Proc. 2017;92(3):423-33.

29. Higgins JPT, Thompson SG. Quantifying heterogeneity in a meta-analysis. Stat Med. 2002;21(11): 1539-58.

30. Zhang J, Yu KF. What's the relative risk? A method of correcting the odds ratio in cohort studies of common outcomes. JAMA. 1998;280(19):1690-1.

31. VanderWeele TJ, Ding P. Sensitivity analysis in observational research: introducing the e-value. Ann Intern Med. 2017;167(4):268-74.

32. Kristensen LE, Jakobsen AK, Askling J, Nilsson F, Jacobsson LTH. Safety of etoricoxib, celecoxib, and nonselective nonsteroidal antiinflammatory drugs in ankylosing spondylitis and other spondyloarthritis patients: a Swedish National PopulationBased Cohort Study. Arthritis Care Res. 2015;67(8): 1137-49.

33. DerSimonian R, Laird N. Meta-analysis in clinical trials. Control Clin Trials. 1986;7(3):177-88. 
34. Myocardial Infarctions Among Ankylosing Spondylitis Patients in a Large US Insurance Database [Internet]. ACR Meeting Abstracts. Available from: https://acrabstracts.org/abstract/myocardialinfarctions-among-ankylosing-spondylitis-patientsin-a-large-us-insurance-database/. Cited 25 Aug 2019.

35. Deodhar A, Winthrop KL, Bohn RL, Chan BK, Suruki RY, Stark JL, et al. SAT0272 Do TNF inhibitors impact the comorbidities and extra-articular manifestations, and thereby alter the natural history of ankylosing spondylitis? Ann Rheum Dis. 2018;77(Suppl 2):1000-1000.

36. Vinker Shuster M, Gendelman O, Tiosano S, Comaneshter $\mathrm{D}$, Cohen $\mathrm{AD}$, Amital $\mathrm{H}$. Ischemic heart disease and ankylosing spondylitis-assessing the role of inflammation. Clin Rheumatol. 2018;37(4):1053-8.

37. Goodson NJ, Brookhart AM, Symmons DPM, Silman AJ, Solomon DH. Non-steroidal anti-inflammatory drug use does not appear to be associated with increased cardiovascular mortality in patients with inflammatory polyarthritis: results from a primary care-based inception cohort of patients. Ann Rheum Dis. 2009;68(3):367-72.

38. Lindhardsen J, Gislason GH, Jacobsen S, Ahlehoff O, Olsen AMS, Madsen OR, et al. Non-steroidal anti-inflammatory drugs and risk of cardiovascular disease in patients with rheumatoid arthritis: a nationwide cohort study. Ann Rheum Dis. 2014;73(8):1515-21.
39. Research C for DE and. Vioxx (rofecoxib) Questions and Answers. FDA [Internet]. 2018 Nov 3; Available from: https://www.fda.gov/drugs/postmarket-drugsafety-information-patients-and-providers/vioxxrofecoxib-questions-and-answers. Cited 21 Aug 2019.

40. Gensler L, Gianfrancesco M, Weisman M, et al. OP0198 Combined effects of tumour necrosis factor inhibitors and nsaids on radiographic progression in ankylosing spondylitis. Ann Rheum Dis. 2018;77:148.

41. Ntusi NAB, Francis JM, Sever E, Liu A, Piechnik SK, Ferreira VM, et al. Anti-TNF modulation reduces myocardial inflammation and improves cardiovascular function in systemic rheumatic diseases. Int J Cardiol. 2018;1(270):253-9.

42. Hokstad I, Deyab G, Wang Fagerland M, Lyberg T, Hjeltnes G, Førre $\varnothing$, et al. Tumor necrosis factor inhibitors are associated with reduced complement activation in spondylarthropathies: An observational study. PLoS ONE. 2019;14(7):e0220079.

43. Deodhar A, Mease PJ, McInnes IB, Baraliakos X, Reich K, Blauvelt A, et al. Long-term safety of secukinumab in patients with moderate-to-severe plaque psoriasis, psoriatic arthritis, and ankylosing spondylitis: integrated pooled clinical trial and post-marketing surveillance data. Arthritis Res Ther. 2019;21(1):111. 